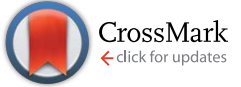

Cite this: RSC Adv., 2017, 7, 11286

Received 27th November 2016 Accepted 26th January 2017

DOI: $10.1039 / c 6 r a 27415 c$

rsc.li/rsc-advances

\section{Ruthenium nanoparticles-modified reduced graphene prepared by a green method for high- performance supercapacitor application in neutral electrolyte $\uparrow$}

\author{
Hagar K. Hassan, ${ }^{a}$ Nada F. Atta, ${ }^{a}$ Maher M. Hamed, ${ }^{a}$ Ahmed Galal ${ }^{\star a}$ \\ and Timo Jacob*bcd
}

Here, we report a one-pot preparation method of a ruthenium-based reduced graphene oxide hybrid $\left(\mathrm{Ru}_{\text {nano-based }} \mathrm{RGO}\right)$. The synthesis is based on a single step for the reduction of $\mathrm{Ru}^{3+}\left(\mathrm{RuCl}_{3}\right)$ into $\mathrm{Ru}$ nanoparticles, and graphene oxide (GO) into reduced graphene oxide (RGO) without the use of any reducing agent. The structure of the hybrid material was ascertained using $X$-ray diffraction (XRD), X-ray photoelectron spectroscopy (XPS), Raman spectroscopy and high resolution transmission spectroscopy (HRTEM). The change in $\mathrm{pH}$ of the synthesis media resulted in different structures and morphologies. A mixture of $\mathrm{Ru}$ and $\mathrm{RuO}_{2}(3: 2)$ was obtained at $\mathrm{pH} 8.0$, while only $\mathrm{Ru}$-nanoparticles were obtained at $\mathrm{pH}$ 4.0. The supercapacitor performance of the hybrid was investigated in a neutral electrolyte, $1.0 \mathrm{M}$

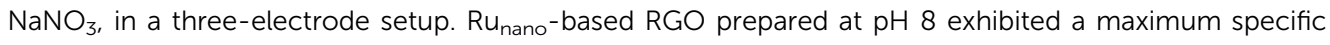
capacitance of $270 \mathrm{~F} \mathrm{~g}^{-1}\left(238.5 \mathrm{mF} \mathrm{cm}{ }^{-2}\right)$, and maximum energy and power densities of $15 \mathrm{~W} \mathrm{~h} \mathrm{~kg}^{-1}$ and $76.4 \mathrm{~kW} \mathrm{~kg}^{-1}$, respectively. The proposed supercapacitor has a stable potential window up to $1.1 \mathrm{~V}$ with very good cycling stability over 5000 cycles at $24 \mathrm{~A} \mathrm{~g}^{-1}$.

\section{Introduction}

Research and technology development for energy sources and storage alternatives are attracting considerable attention. This is because of the depletion of the energy supply from fossil fuels and increasing environmental pollution. ${ }^{1}$ Another challenge is electricity storage with high power and energy densities. ${ }^{2}$

Electric double layer capacitors (EDLCs) are promising energy storage devices that store electric charges at the interface between the electrode surface and the electrolyte. ${ }^{3}$ Another class of capacitors is pseudocapacitors, in which the capacitance arises from a reversible reaction that takes place at the interface. Both EDLCs and pseudocapacitors belong to the class of supercapacitors or ultracapacitors due to their high specific capacitance compared to conventional capacitors. Moreover, supercapacitors provide several advantages over batteries such as high power density, long cycling stability, fast charging/ discharging rate and lower environmental impact. ${ }^{4}$

${ }^{a}$ Department of Chemistry, Faculty of Science, Cairo University, 12613 Giza, Egypt. E-mail: galal@sci.cu.edu.eg

${ }^{b}$ Institute of Electrochemistry, Ulm University, 89081 Ulm, Germany. E-mail: timo. jacob@uni-ulm.de

${ }^{c}$ Helmholtz-Institute-Ulm (HIU) [d], Helmholtzstr. 11, 89081 Ulm, Germany ${ }^{d}$ Karlsruhe Institute of Technology (KIT), P.O. Box 3640, 76021 Karlsruhe, Germany $\dagger$ Electronic supplementary information (ESI) available. See DOI: $10.1039 / \mathrm{c} 6 \mathrm{ra} 27415 \mathrm{c}$
Supercapacitors however have lower energy densities compared to batteries. Research work on the usage of energy storage devices is targeting the enhancement of the properties of supercapacitors for usage in many applications. Beside the low energy density of supercapacitors, pseudocapacitors have poor cycling stability. ${ }^{5}$ Construction of hybrid materials (for combination between EDLCs and pseudocapacitors) is one of the challenges to overcome the problem of both EDLCs and pseudocapacitors and to improve the properties of supercapacitors. ${ }^{6}$ This might allow for a maximum energy density at high power density without sacrificing the cycling stability.

In recent years, graphene attracted a significant interest as a promising electrode material for energy storage applications. ${ }^{7}$ Graphene-based supercapacitors showed high theoretical specific capacitance up to $550 \mathrm{~F} \mathrm{~g}^{-1.8}$ Since restacking or aggregation of its sheets due to van der Waals forces limits reaching its theoretical specific capacitance value in real applications, modifying the graphene sheets in order to avoid their aggregation is of prime importance.

Transition metals and their oxides are interesting candidates to act as spacers between graphene sheets to prevent their aggregation and hence, to increase the specific capacitance of graphene-based supercapacitors. ${ }^{5} \mathrm{Here}, \mathrm{RuO}_{2}$ is one of the most promising materials for supercapacitor applications due to its high specific capacitance from 1300 to $2200 \mathrm{~F} \mathrm{~g}^{-1}, \mathbf{9 , 1 0}$ high rate capability, highly reversible faradic reaction and high thermal 
stability. ${ }^{\mathbf{1 1}}$ However, Ru-based materials are usually suffering from their poor porosity, less cycling stability and rapid decrease of power density especially at high charge/discharge rates as well as the high price of $\mathrm{Ru}$-based materials that limits their commercial use. ${ }^{5}$ The properties of Ru-based materials (i.e. $\mathrm{Ru}, \mathrm{RuO}_{2}$ and $\mathrm{Ru}$-based perovskites) can be strongly altered by changing the method of their preparation or changing the material they are grown over. There are several works related to the preparation of $\mathrm{RuO}_{2}$ over various carbon materials such as mesoporous carbon, ${ }^{12}$ activated carbon, ${ }^{\mathbf{5}}$ graphene $\mathrm{e}^{\mathbf{1 0 , 1 3 - 1 7}}$ or carbon nanotubes. ${ }^{18}$ However, extra improvement is still required because almost all of the previous $\mathrm{RuO}_{2}$-based carbon supercapacitors are limited to operate in either highly acidic or basic electrolytes. This is in order to harvest the benefits of the high capacitance value of $\mathrm{RuO}_{2}$ in spite of the fact that such electrolytes are not targets for the next generation of supercapacitors due to environmental issues. Additionally, some of the previous methods require long preparation times, sophisticated preparation methods, the use of hazardous materials or further annealing steps. Therefore, it is preferred to construct a supercapacitor based on Ru-based materials, using a neutral electrolyte as well as a preparation method based on a "green" and simple (e.g. one-step) method. This can be achieved by tuning the structure and/or morphology of Ru-based materials through changing its preparation method, so that for instance nanoparticulate materials can be obtained. Wang et al. ${ }^{9}$ reported the preparation of Ru-based materials with smaller particle size decreasing the diffusion resistance, facilitating the proton transport in the bulk of $\mathrm{RuO}_{2}$ and increasing the specific capacitance as well as the storage efficiency.

In this work, we introduce the synthesis of Ru/RGO via a onestep, green and efficient method and its application as a supercapacitor electrode in a neutral electrolyte. The current method is based on the simultaneous reduction of a $\mathrm{Ru}$ precursor and GO in a single step and without using any reducing agent and under $\mathrm{pH}$ control. The mass percentage of the $\mathrm{Ru}$ precursor does not exceed $25 \%$ of the total weight of the material in order to minimize the cost of the capacitor. The proposed preparation method is accomplished without any annealing or calcination process. This is advantageous in reducing the energy consumption during the preparation step.

\section{Experimental}

\subsection{One-step preparation of Ru-RGO}

Graphene oxide was prepared by a modification of Hummer's method, following the same procedure as reported previously. ${ }^{19}$ Briefly, $5 \mathrm{~g}$ of high purity graphite was cured with $\mathrm{H}_{2} \mathrm{SO}_{4}, \mathrm{P}_{2} \mathrm{O}_{5}$ and $\mathrm{K}_{2} \mathrm{~S}_{2} \mathrm{O}_{8}$ in order to prepare the per-oxidized graphite. This is followed by stirring $5 \mathrm{~g}$ of dried per-oxidized graphite with 115 $\mathrm{mL}$ of concentrated $\mathrm{H}_{2} \mathrm{SO}_{4}$ in an ice bath for about 10 minutes, then $15 \mathrm{~g}$ of $\mathrm{KMnO}_{4}$ was gradually added and stirring was continued for two more hours. The mixture acquired a bright yellow color after its dilution by water and treatment with $\mathrm{H}_{2} \mathrm{O}_{2}$. The bright yellow suspension was filtered and washed with $1: 10 \mathrm{HCl}$ solution, afterwards it was dried overnight at $80^{\circ} \mathrm{C}$ in an oven. Ru/RGO was prepared by adding $0.2 \mathrm{~g}$ of GO to $0.069 \mathrm{~g}$ of $\mathrm{RuCl}_{3}$ and dissolved in distilled water followed by ultrasonication of the mixture for two hours. Ammonia solution was used to adjust the $\mathrm{pH}$ of the suspension to (2.0, 4.0 and 8.0), then it was placed in a conventional microwave that was operated at $720 \mathrm{~W}$ using $30 \mathrm{~s}$ cycles (20 s: on and $10 \mathrm{~s}$ : off) until the ignition process takes place; the total reaction time is 30 minutes. During the irradiation, the suspension becomes viscous with time and dehydrated. The resulting powder was ignited and a strong firing takes place, resulting in a black powder that indicates the successful reduction of RGO. For comparison, the chemically reduced graphene oxide (RGO) was also prepared following the procedure mentioned in ref. 20.

\subsection{Structural, spectral and surface analysis}

The prepared materials were characterized using X-ray diffraction (XRD), Raman spectroscopy, X-ray photoelectron spectroscopy (XPS), field-emission scanning electron microscope (FESEM) with energy-dispersive analysis by X-ray (EDX) and high-resolution transmission electron microscope (HR-TEM), the XRD was recorded by Panlytical X'Pert using $\mathrm{Cu}-\mathrm{K}_{\alpha}$ radiation $(\lambda=1.540 \AA)$, the Raman spectra were obtained using Witec alpha 300R confocal Raman microscope with a $532 \mathrm{~nm} \mathrm{Nd:Yag}$ laser. XPS measurements were performed with a Perkin Elmer 5300 XPS system with a non-monochromatised $\mathrm{Mg}-\mathrm{K}_{\alpha}$ X-ray source. Calibration was performed using the $\mathrm{C} 1 \mathrm{~s}$ component (binding energy is $284.6 \mathrm{eV}$ ). An $\mathrm{Mg}-\mathrm{K}_{\alpha} \mathrm{X}$-ray was used with $300 \mathrm{~W}$ applied to the anode. The surface morphological analysis was performed using HR-TEM (Tecnai G20, FEI, Netherland, $200 \mathrm{kV}$, LaB6 Gun), FESEM and EDX (JEOL JSM-6360LA and Philips XL30).

\subsection{Electrode fabrication and electrochemical measurements}

An amount of $20 \mathrm{mg}$ of the prepared $\mathrm{Ru}_{\text {nano-based } \mathrm{RGO} \text { was }}$ sonicated with $1 \mathrm{~mL}$ of dimethyl formamide (DMF) for about 30 minutes in order to prepare a homogeneous suspension of $20 \mathrm{mg} \mathrm{mL}{ }^{-1} \mathrm{Ru}-\mathrm{RGO}$ suspension. By the same way we also prepared $20 \mathrm{mg} \mathrm{mL}^{-1}$ of RGO (sonicated until a homogeneous suspension obtained). The electrodes used for the electrochemical capacitance measurements were prepared by adding 5 $\mu \mathrm{L}$ of $2 \%$ Nafion solution on the surface of well-polished mirrorlike Ni electrodes of diameter $0.6 \mathrm{~cm}$ (surface area $0.283 \mathrm{~cm}^{2}$ ) and connected with a copper rod for electrical conductivity. Then the Ni/Nafion electrode was dried at $80{ }^{\circ} \mathrm{C}$ followed by

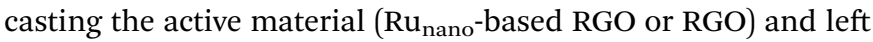
to dry in an oven in order to obtain $\mathrm{Ni} / \mathrm{N} / \mathrm{Ru}_{\text {nano }}$-based $\mathrm{RGO}$ and $\mathrm{Ni} / \mathrm{N} / \mathrm{RGO}$. The masses of the electroactive materials were

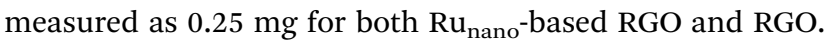

The electrochemical measurements were performed in a conventional three-electrode system using $\mathrm{Ag} / \mathrm{AgCl}(4.0 \mathrm{M} \mathrm{KCl})$ as reference electrode and a Pt wire as counter electrode. Cyclic voltammetry and galvanostatic charging/discharging experiments were performed using a Voltalab PGZ301 potentiostat. Electrochemical impedance spectroscopy (EIS) was performed using the same instrument at OCP from $100 \mathrm{mHz}$ to $100 \mathrm{kHz}$ with 
an AC amplitude of $10 \mathrm{mV}$. Cyclic voltammetry curves were recorded from $E_{\mathrm{i}}=0.0 \mathrm{~V}$ to $E_{\mathrm{f}}=0.7,0.8,0.9,1.0$ and $1.1 \mathrm{~V}$ at scan rates ranging from 5.0 to $200 \mathrm{mV} \mathrm{s}^{-1}$. Galvanostatic charging/ discharging curves were recorded using chronopotentiometry at various current densities ranging from $1.0 \mathrm{~A} \mathrm{~g}^{-1}$ to $26 \mathrm{~A} \mathrm{~g}^{-1}$ and limiting the potential between $0.0 \mathrm{~V}$ to $0.9 \mathrm{~V}$. The specific capacitance was calculated from cyclic voltammetry using eqn (1) and from galvanostatic charging-discharging data using eqn (2). Eqn (3) and (4) are used to calculate the energy and the power densities, respectively.

$$
\begin{gathered}
C_{\mathrm{sp}}=\frac{\bar{I}}{\nu m \Delta V} \\
C_{\mathrm{sp}}=\frac{I t_{\mathrm{d}}}{m \Delta V} \\
E=\frac{\frac{1}{2} C_{\mathrm{s}} \Delta V^{2}}{3.6} \\
P=\frac{E}{t_{\mathrm{d}}} \times 3600
\end{gathered}
$$

$\bar{I}$ is the integration of area enveloped inside the CVs, $\Delta V$ is the potential window in volts $\left(V_{\mathrm{f}}-V_{\mathrm{i}}\right), \nu$ is the scan rate, $C_{\mathrm{sp}}$ is the specific capacitance in $\mathrm{F} \mathrm{g}^{-1}, m$ is the mass of electroactive material in grams, $I$ is the current in ampere, and $t_{\mathrm{d}}$ is the discharge time in seconds. For measuring power density and energy density $I R$ drop was excluded from potential value. The factors 3.6 and 3600 comes from the unit conversions of time and mass from $\mathrm{g}$ to $\mathrm{kg}$ and from $\mathrm{s}$ to $\mathrm{h}$, respectively.

\section{Results and discussion}

By changing the preparation method one is able to form particles of different morphologies, sizes and of different structures as well. This should additionally alter the electric and electrochemical properties of the final hybrid. Hence, in the current study we investigated the effect of microwave irradiation on the precursors GO and $\mathrm{RuCl}_{3}$ in the absence of any reducing, stabilizing or precipitating agents. The microwave irradiation was used to provide a simultaneous reduction of both GO and $\mathrm{Ru}^{3+}$, and the structure of the obtained material was investigated. Microwave chemistry is the science that uses microwave irradiation to boost chemical reactions. ${ }^{21}$ There are two main heating mechanisms during the microwave irradiation; dipolar polarization and ionic conduction. Generally, microwave heats any polar molecules such as water or the conducting ions in a solvent or in a solid. Dipolar mechanism includes the reorientation of water molecules under the effect of alternating electric field. The frictions and collisions between molecules during the reorientation as well as the rotation are responsible for the heating effect. ${ }^{21}$ In the case of ions, the ionic conduction is based on the movement of ions in the solution under the effect of the orientation of the electric field. And since the fluctuation of the electric field is constant, the direction of ions movement is constant through the solution. This will result in an increase in the temperature due to frictions and collisions.
So, the semiconducting or conducting samples heat up when their ions lose their electric energy that is generated during the irradiation. This loss in the electric energy is due to the electrical resistance of the materials. ${ }^{22}$ Microwave chemistry is therefore based on the efficient superheating of the material so that the product may acquire different properties. There is extensive work using microwave irradiation to reduce metal nanoparticles in the presence of a reducing agent such as hydrazine hydrate, urea, sodium borohydride, sugar, sodium citrate, citric acid, etc. ${ }^{22}$ The use of some of these compounds such as citric acid as a reducing agent is based upon the formation of a complex with metal salts. GO contains in its structure oxygenated functional groups that can form a complex with many metal salts. This complex facilitates the reduction of metal ions into metal nanoparticles as a result of the high density of electrons on the GO surface.

\subsection{Surface, structural and spectral characterization}

3.1.1 X-ray diffraction (XRD). X-ray diffraction is a very useful tool providing information on the structure of the crystalline material as well as the predominance of one phase over the other in case of the presence of different phases. XRD patterns of

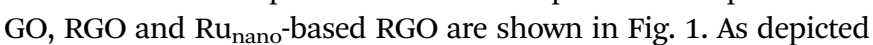
in Fig. 1a, GO showed a strong diffraction peak at $2 \theta=8.78^{\circ}$ with a $d$-spacing of $10.05 \AA$, while RGO showed a broad hump at $26.5^{\circ}$ corresponding to the (002) plane. On the other hand, $\mathrm{Ru}_{\text {nano-based }}$ RGO showed a weak diffraction peak at $26.6^{\circ}$ with a $d$-spacing 3.34 $\AA$ related to the (002) plane, which gives an indication of the successful reduction of GO as depicted in Fig. 1b. The XRD pattern

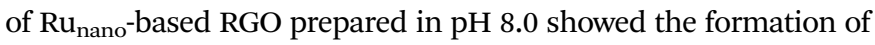
$\mathrm{Ru}$ nanoparticles, as indicative by the diffraction peak at $43.97^{\circ}$ corresponding to the (101) plane with a $d$-spacing of $2.058 \AA$. These values are in very good agreement with the reference card (04-0030364). In the same time, $\mathrm{RuO}_{2}$ is also formed as a secondary phase with the main diffraction pattern at $28.02^{\circ}$ ( $d$-spacing of $3.184 \AA$ ), according to reference card number (00-040-1290), with a relative intensity of $64.7 \%$. This indicates that at $\mathrm{pH} 8$ a mixture of $\mathrm{Ru}$ nanoparticles and $\mathrm{RuO}_{2}$ was formed in $3: 2$ ratio.

It is worth mentioning that this is the first time $\mathrm{Ru}_{\text {nano-based }}$ RGO with Ru-rich composition was prepared without any reducing agent. The microwave irradiation provided enough energy to successfully reduce both $\mathrm{GO}$ and $\mathrm{Ru}^{3+} \cdot \mathrm{RuCl}_{3}$ dissolved in water forms hydroxyl-salts of $\mathrm{Ru}$ of the type $\left[\mathrm{Ru}(\mathrm{OH})_{x}\right.$, $\mathrm{Cl}_{3-x}$ ] (see eqn (5)). In the presence of high concentrations of $\mathrm{NH}_{4}(\mathrm{OH}),\left[\mathrm{Ru}(\mathrm{OH})_{x}, \mathrm{Cl}_{3-x}\right]$ leads to the formation of $\mathrm{Ru}(\mathrm{OH})_{3}$. Further oxidation results in the formation of the corresponding oxide according to eqn (5)-(9). ${ }^{13}$ The major fraction of ruthenium ions are bonded to the surface of graphene and consequently reduced on the RGO surface, forming Ru nanoparticles.

$$
\begin{gathered}
\mathrm{RuCl}_{3} \cdot n \mathrm{H}_{2} \mathrm{O}+\mathrm{H}_{2} \mathrm{O} \rightarrow \mathrm{Ru}(\mathrm{OH})_{x} \mathrm{Cl}_{3-x}+x \mathrm{H}^{+}+x \mathrm{Cl}^{-} \\
\mathrm{NH}_{4} \mathrm{OH} \leftrightarrow \mathrm{NH}_{4}^{+}+\mathrm{OH}^{-} \\
\mathrm{Ru}(\mathrm{OH})_{x} \mathrm{Cl}_{3-x}+3 \mathrm{OH}^{-} \rightarrow \mathrm{Ru}(\mathrm{OH})_{3}+x \mathrm{OH}^{-}+(3-x) \mathrm{Cl}^{-} \\
2 \mathrm{Ru}(\mathrm{OH})_{3}+\frac{1}{2} \mathrm{O}_{2}+\mathrm{H}_{2} \mathrm{O} \rightarrow 2 \mathrm{Ru}(\mathrm{OH})_{4}
\end{gathered}
$$




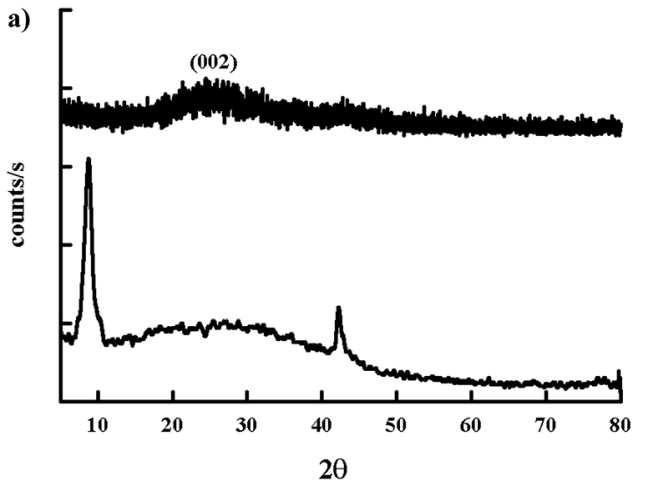

b)
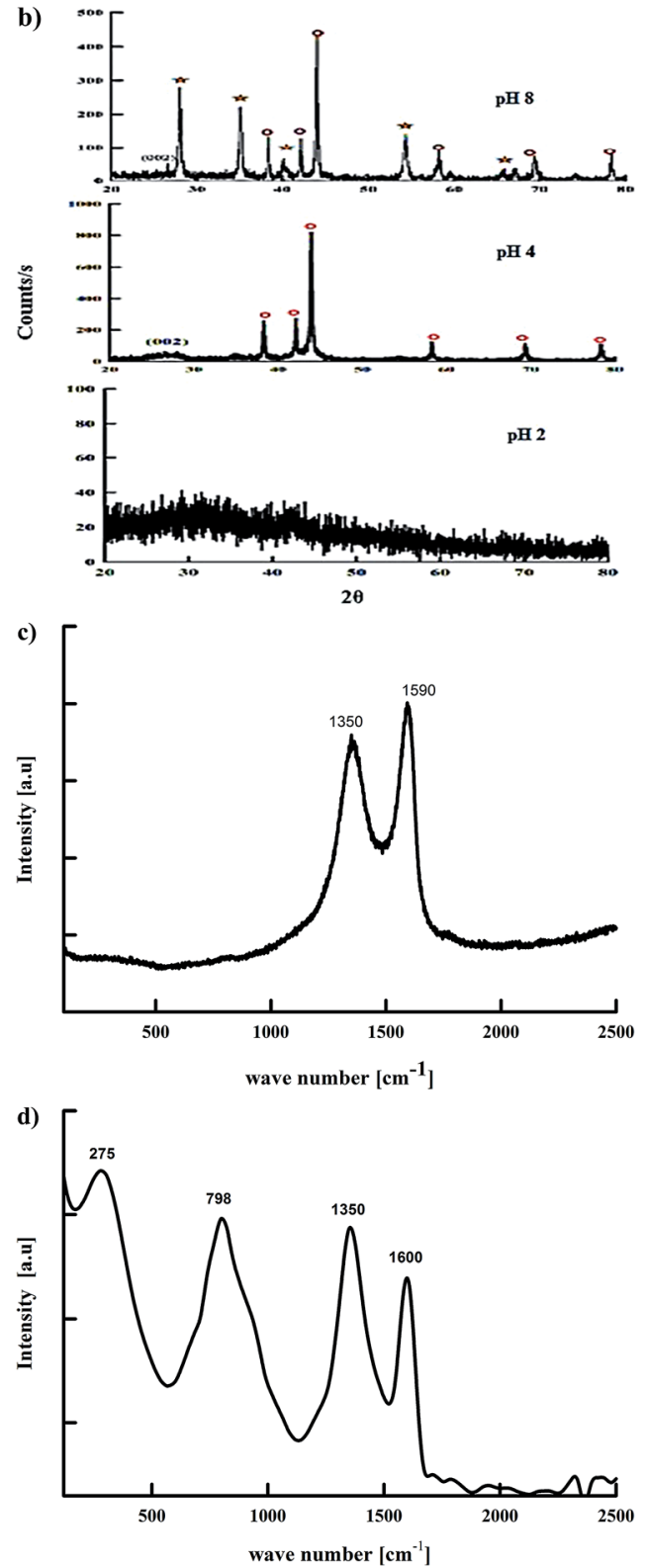

Fig. 1 XRD of (a) GO and RGO, (b) Runano-based RGO (prepared at $\mathrm{pH}$ 2, 4 and 8) (circles are related to the phases of Ru and stars are related to $\mathrm{RuO}_{2}$ ), (c) Raman spectra of $\mathrm{GO}$ and (d) Raman spectra of $\mathrm{Ru}_{\text {nano- }}$ based RGO (pH 8).

$$
\mathrm{Ru}(\mathrm{OH})_{4}+(n-2) \mathrm{H}_{2} \mathrm{O} \rightarrow \mathrm{RuO}_{2} \cdot n \mathrm{H}_{2} \mathrm{O}
$$

As the $\mathrm{pH}$ of the precursors strongly affects the prepared material, we also investigated the influence of $\mathrm{pH}$ on the initial solution of hydrated $\mathrm{RuCl}_{3}$ and $\mathrm{GO}$ on the obtained composite structure. As shown in Fig. 1b the sample prepared at $\mathrm{pH} 4.0$ contains solely Ru nanoparticles, where decorated RGO is the phase obtained without the formation of $\mathrm{RuO}_{2}$. Wang et al. ${ }^{9}$ reported that $\mathrm{Ru}$ nanoparticle formation is favored at $\mathrm{pH}$ values less than 4.9. At $\mathrm{pH} 4.0 \mathrm{Ru}^{3+}$ ions are bound to GO sheets via complexation that helps reducing $\mathrm{Ru}^{3+}$ ions into $\mathrm{Ru}$ nanoparticles that are strongly attached to RGO sheets as a result of a high electron density on the GO surface. On the other hand, the sample prepared at $\mathrm{pH} 2.0$ does not show any diffraction peaks, indicating an amorphous-like structure. This leads to the conclusion that $\mathrm{pH} 2.0$ is not suitable for preparation of neither crystalline $\mathrm{Ru}$ nor $\mathrm{RuO}_{2}$. This is due to the strong acidic solution favoring "free" ionic formation and minimizing the possible reduction of $\mathrm{Ru}^{3+}$ ions to bind "in situ" onto RGO. However, the firing process that occurred during the microwave irradiation of the sample results in the reduction of GO into RGO as indicated by the absence of GO-related peaks. Hence, only samples prepared at $\mathrm{pH} 4.0$ and 8.0 were electrochemically tested as supercapacitor electrodes.

3.1.2 Raman spectroscopy. Raman spectra of GO (see Fig. 1c) are characterized by two strong peaks at $1350 \mathrm{~cm}^{-1}$ corresponding to the D-band that arises from a breathing mode of $K$-point phonons of $\mathrm{A}_{1 \mathrm{~g}}$ symmetry and the second peak at $1600 \mathrm{~cm}^{-1}$, corresponding to the G-band that arises from the first scattering of $\mathrm{E}_{2 \mathrm{~g}}$ phonon of $\mathrm{sp}^{2}$ carbon atoms. These two bands are characteristic for RGO as well, while the difference in the spectra of GO and RGO is the intensity ratio of D-band to Gband. Increased $\mathrm{D} / \mathrm{G}$ ratio indicates a successful reduction of GO into RGO. The spectra of $\mathrm{Ru}_{\text {nano-based }} \mathrm{RGO}$ (pH 8) (Fig. 1d) shows the D-band of RGO at $1348 \mathrm{~cm}^{-1}$ and G-band at 1600 $\mathrm{cm}^{-1}$, where the $\mathrm{D} / \mathrm{G}$ ratio increases in case of $\mathrm{Ru}_{\text {nano-based }}$ $\mathrm{RGO}(\mathrm{pH} 8)$ from 0.89 to 1.11 as indicator of the successful reduction of GO to RGO. The red shift of the D-band arises from the presence of Ru-based material as a spacer between RGO

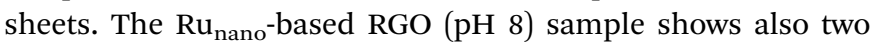
relatively broad peaks at $285 \mathrm{~cm}^{-1}$ and $798 \mathrm{~cm}^{-1}$, corresponding to the symmetric $\mathrm{A}_{1 \mathrm{~g}}$ vibration of $\mathrm{Ru}-\mathrm{O}$ and $\mathrm{B}_{2 \mathrm{~g}}$ of $\mathrm{RuO}_{2}$, respectively. ${ }^{23,24}$

3.1.3 X-ray photoelectron spectroscopy (XPS). The XPS analysis is a powerful tool to identify elements and the possible structure of a compound or a composite material. Fig. 2 shows

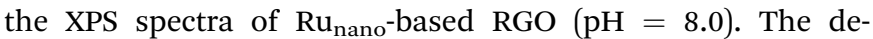
convoluted photoemission peaks show Ru-3p $\mathrm{p}_{1 / 2}$ and $3 \mathrm{p}_{3 / 2}$ at $484 \mathrm{eV}$ and $461.8 \mathrm{eV}$, respectively, confirming the presence of $\mathrm{Ru}$ and $\mathrm{RuO}_{2}$ nanoparticles in the composite. ${ }^{25} \mathrm{Ru}$-3d peaks are observed at 284.9 and $279.9 \mathrm{eV}$, corresponding to $\mathrm{Ru}-3 \mathrm{~d}_{3 / 2}$ and $\mathrm{Ru}-3 \mathrm{~d}_{5 / 2}$ and related to $\mathrm{RuO}_{x}$ and $\mathrm{Ru}$ nanoparticles, respectively. ${ }^{26,27}$ It is worth to mention that the total content of $\mathrm{RuO}_{2}$ and $\mathrm{Ru}$ in the sample is $5.2 \%(3.15 \% \mathrm{Ru}$ nanoparticles and $2.08 \% \mathrm{RuO}_{2}$ ).

The de-convolution of C-1s showed four peaks at 287.6, $286.8,285.7$ and $284.6 \mathrm{eV}$ that can be assigned to $\mathrm{C}=\mathrm{O}, \mathrm{COO} /$ 

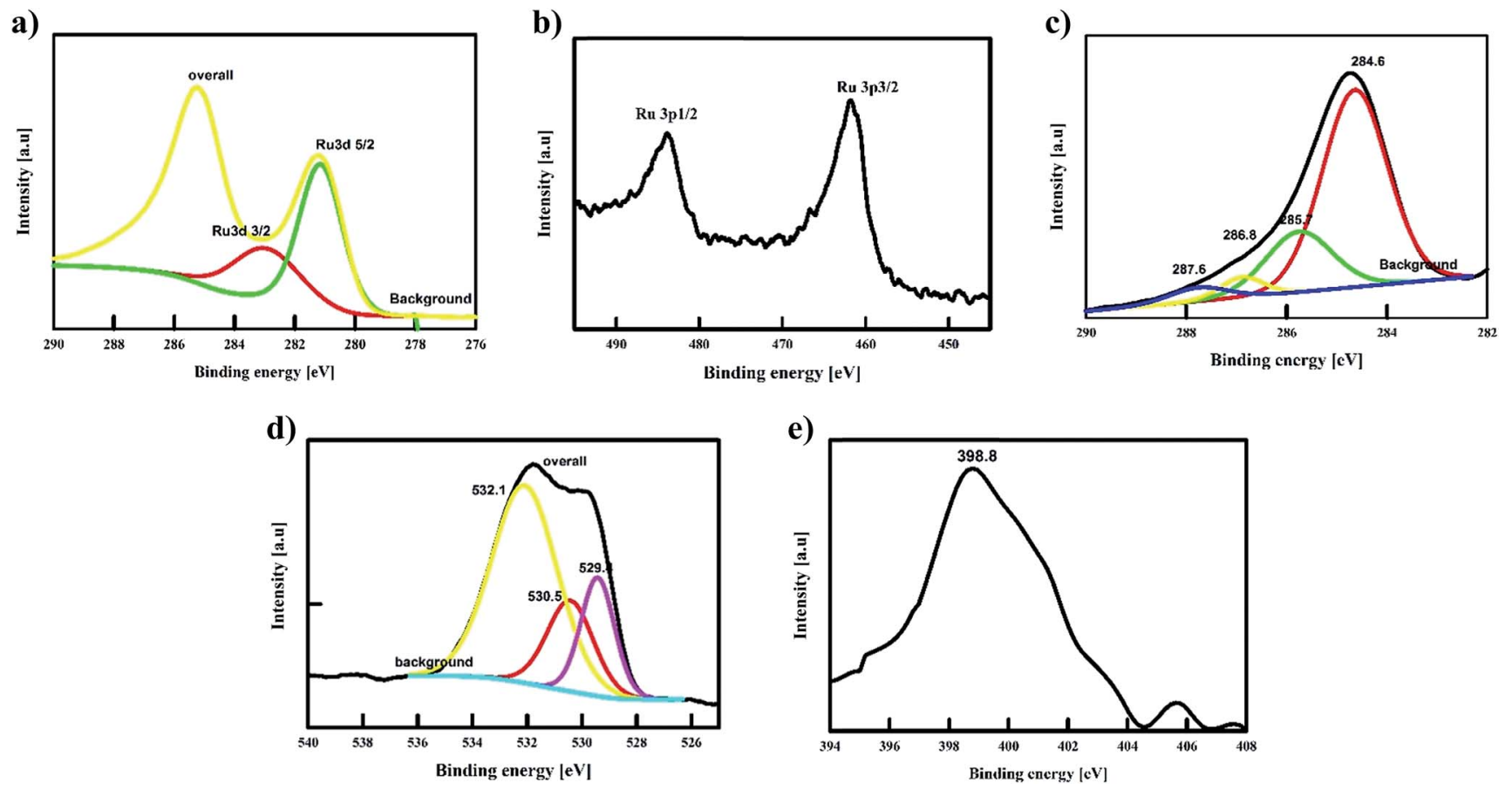

Fig. 2 XPS spectra of Runano-based RGO (pH 8) shows the deconvoluted peaks of Ru 2p, Ru 3d, C 1s, O 1s and N 1s.

$\mathrm{COH}, \mathrm{C}-\mathrm{O}$ and $\mathrm{C}=\mathrm{C} / \mathrm{C}-\mathrm{H}$. The relative intensity of $\mathrm{C}-\mathrm{C} / \mathrm{C}=\mathrm{C}$ compared to the oxygenated peaks as well as the corresponding peak area are used to evidence the successful reduction of GO into RGO. As depicted in the C-1s spectra of GO before its reaction (Fig. $\mathrm{S} 1 \dagger$ ), the $\mathrm{C}-\mathrm{C} / \mathrm{C}=\mathrm{C}$ peak to the oxygenated peak

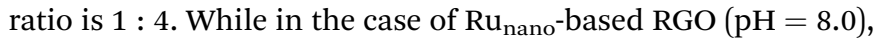
$\mathrm{C}-\mathrm{C} / \mathrm{C}=\mathrm{C}$ to the oxygenated peaks ratio is relatively higher compared to the case of GO as shown in Fig. 2c. In the latter case, the ratio is about $1.02: 1.0$ that confirms the successful reduction of GO into RGO. Moreover, the peaks of the O-1s spectra at $232.1 \mathrm{eV}$ and $230.5 \mathrm{eV}$ are assigned to the graphenic oxygen, while the peak at $229.4 \mathrm{eV}$ corresponds to the oxygen of $\mathrm{RuO}_{2}$. Additionally, the presence of nitrogen-doped graphene is confirmed by the $\mathrm{N}-1$ s peak at $398.78 \mathrm{eV}$ that corresponds to the $\mathrm{N}-\mathrm{C}$ bond, indicating the formation of $\mathrm{N}$-doped graphene, which in turn plays a crucial role in separating graphene sheets and preventing their restacking.

3.1.4 TEM analysis. The TEM image of $\mathrm{Ru}_{\text {nano }}$-based RGO $(\mathrm{pH}=8.0)$ is shown in Fig. 3a, clearly indicating that the $\mathrm{Ru}-$ based materials ( $\mathrm{Ru}$ and $\mathrm{RuO}_{2}$ ) are uniformly distributed on the surface of RGO sheet. The presence of both $\mathrm{Ru}$ and $\mathrm{RuO}_{2}$ has been confirmed from selected area electron diffraction (SEAD) pattern by calculating the $d$-spacing(s) and correlating them to those in the reference cards of both $\mathrm{Ru}$ and $\mathrm{RuO}_{2}$. By the aid of the SEAD pattern we can calculate the average particle size of $\mathrm{Ru}$ and $\mathrm{RuO}_{2}$ nanoparticles and differentiate between them. The SEAD pattern (Fig. 3c) of a selected area indicates that the particles of this area are mainly $\mathrm{Ru}$ with and averaged size of 1-3 $\mathrm{nm}$. While by selecting another area (Fig. 3c), in which only $\mathrm{RuO}_{2}$ has been investigated, and by the aid of the SEAD pattern (Fig. 3d), we found that some $\mathrm{RuO}_{2}$ nanoparticles form small clusters with a maximum size of $16 \mathrm{~nm}$. The images further indicate that some $\mathrm{Ru}$ nanoparticles are embedded into the RGO sheets.

\subsection{Electrochemical characterization}

The electrochemical behavior of Ru-based graphene as supercapacitor electrode depends on the main phase within the structure. ${ }^{\mathbf{1 0 1 3 - 1 7}}$ The main phase formed is $\mathrm{RuO}_{2}$ with the possible formation of some $\mathrm{Ru}$ nanostructures as minor phase. ${ }^{10,13-17}$ As it was anticipated in this work, $\mathrm{Ru}_{\text {nano }}$ has the

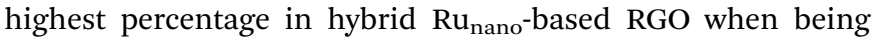
prepared at $\mathrm{pH} 8.0$ and is the only phase at $\mathrm{pH}$ 4.0.

Often $\mathrm{H}_{2} \mathrm{SO}$ and $\mathrm{KOH}$ are used as electrolytes in supercapacitors and pseudocapacitors measurements. Relatively high concentrations of these electrolytes are recommended in order to decrease the equivalent series resistance (ERS). While higher power densities are expected, the corrosive nature of the concentrated acid or base results in the deterioration of current collectors and their leakage will be detrimental, especially on decreasing the cycling stability of the capacitor. Limitation of the operating potential windows in acidic ${ }^{13,28}$ and $\operatorname{basic}^{11,29}$ electrolytes is another drawback.

$\mathrm{RuO}_{2}$-based supercapacitors have been reported to operate in highly concentrated $\mathrm{H}_{2} \mathrm{SO}_{4}{ }^{30,31}$ and many researchers suggested that $\mathrm{RuO}_{2}$-based supercapacitors are suitable only in such electrolytes. ${ }^{13,28}$ A high pseudocapacitance was obtained due to a surface reaction between $\mathrm{Ru}$ ions and protons $\left(\mathrm{H}^{+}\right)$in acidic media according to eqn (10):

$$
\mathrm{RuO}_{a}(\mathrm{OH})_{b}+\sigma \mathrm{H}^{+}+\sigma \mathrm{e}^{-} \leftrightarrow \mathrm{RuO}_{a-\sigma}(\mathrm{OH})_{b+\sigma}
$$


a)

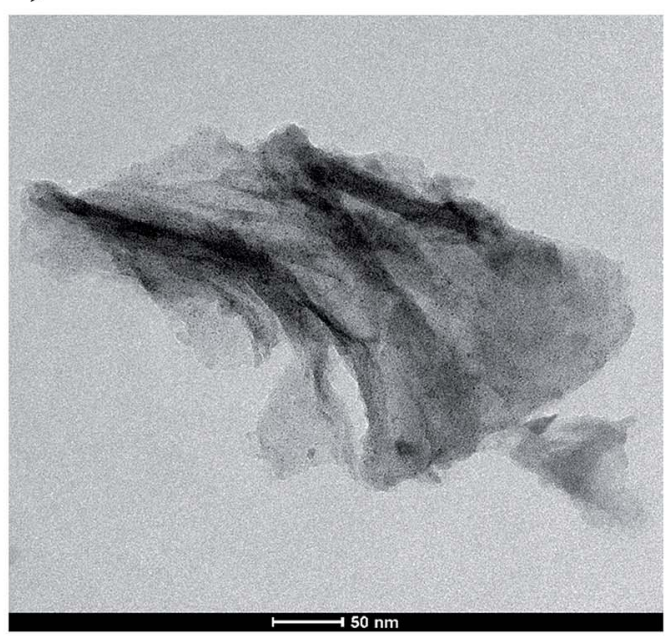

b)

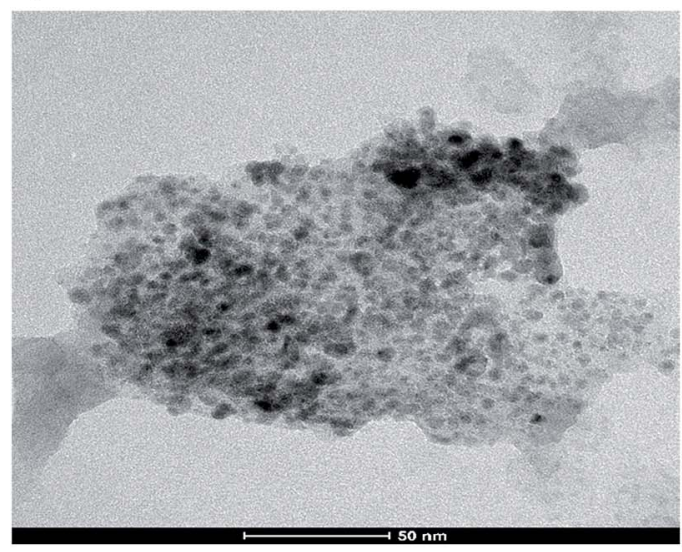

d)

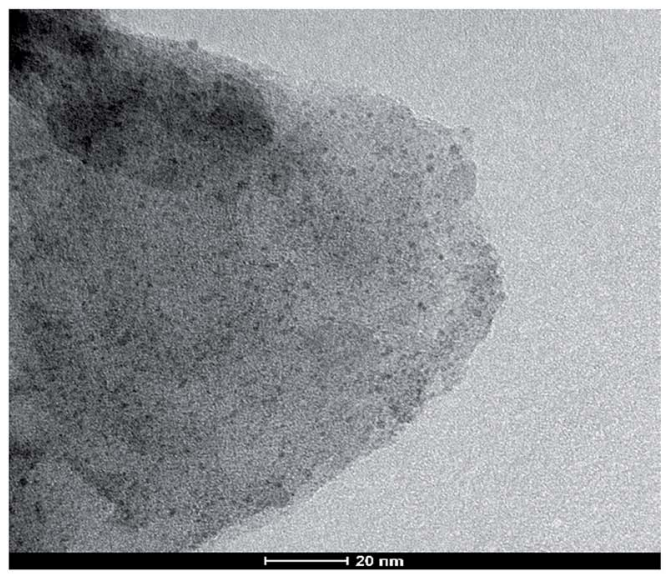

c)

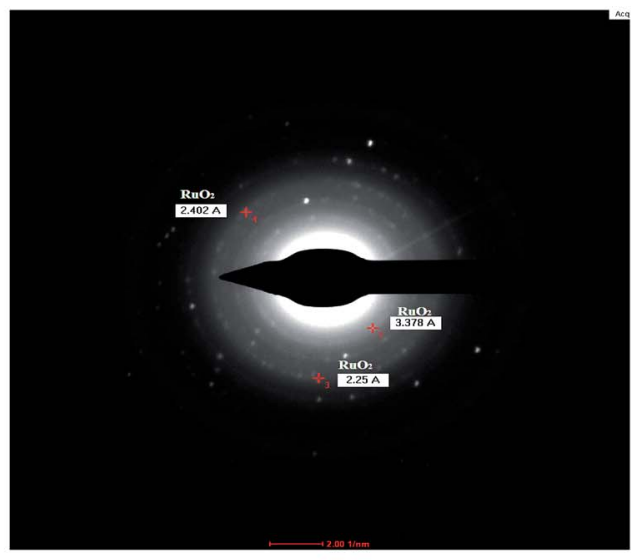

e)

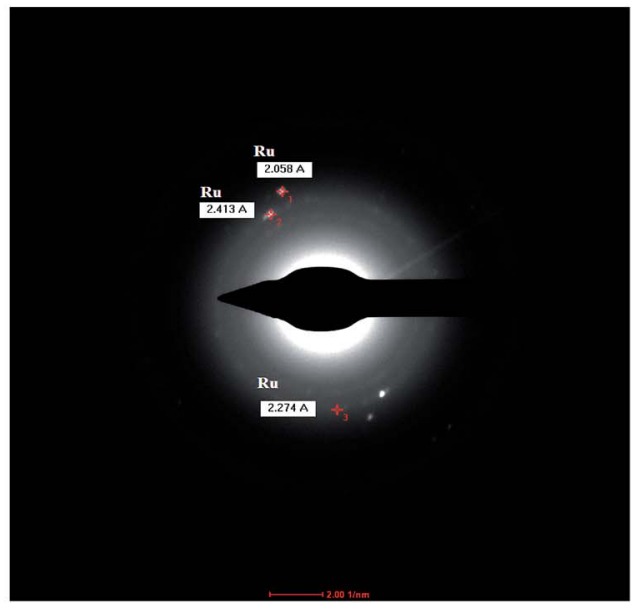

Fig. 3 (a) TEM of Runano-based RGO (pH 8) (b) zoom in TEM of Runano-based RGO (pH 8) showing Ru nanoparticles and (c) its corresponding

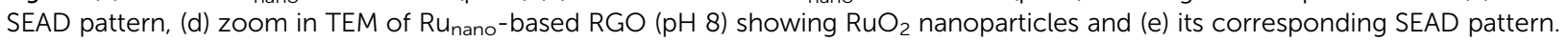

Using a neutral electrolyte not only solves the corrosion problem but also allows the supercapacitor to operate at a wider potential window. ${ }^{30}$
3.2.1 Cyclic voltammetry measurements. The electrochemical capacitance of the obtained Ru-based RGO (prepared at $\mathrm{pH} 4.0$ and 8.0 ) as well as RGO has been tested by cyclic 
a)

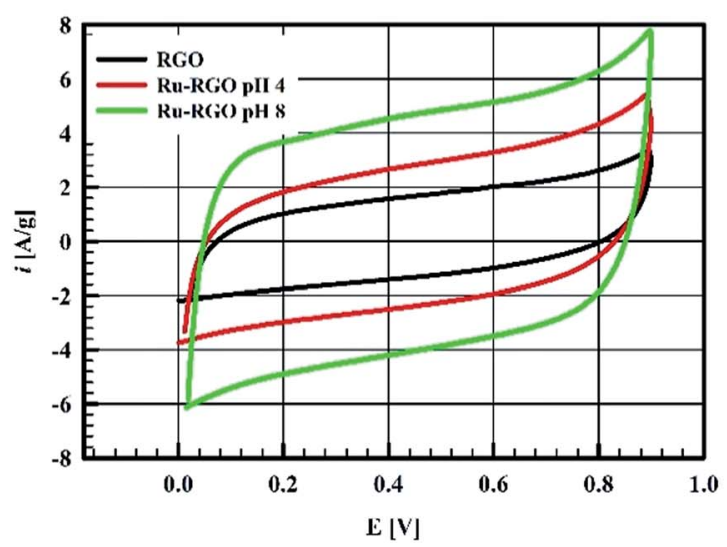

c)

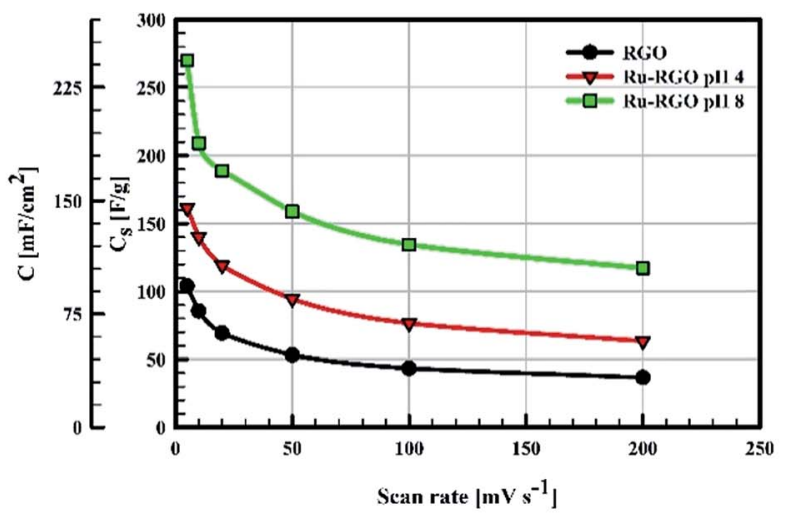

b)

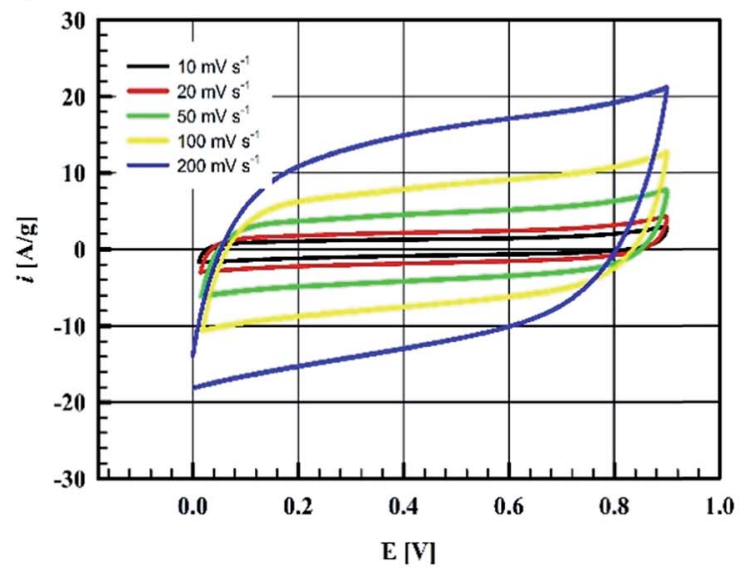

d)

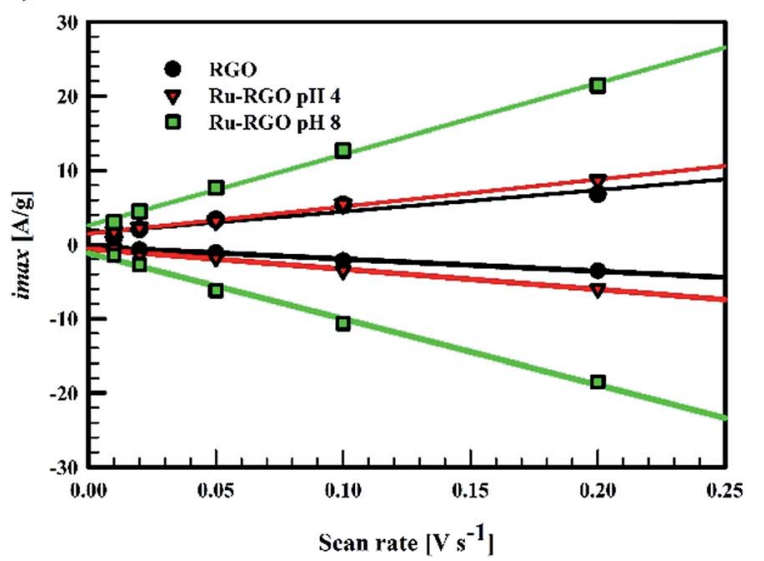

e)

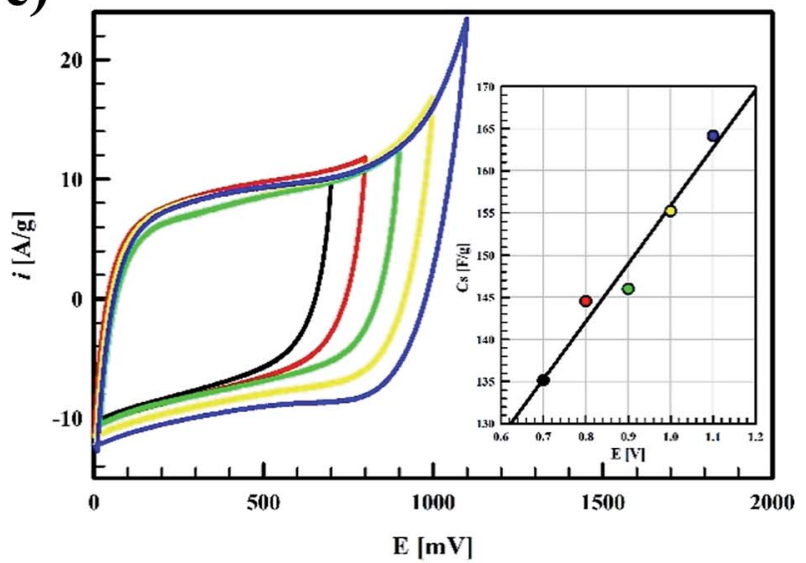

Fig. 4 (a) $\mathrm{CV}$ of RGO (black line), Runano-based RGO (pH 4) (red line) and Runano-based RGO (pH 8) (green line) measured at scan rate 50 mV $\mathrm{s}^{-1}$ in $1 \mathrm{M} \mathrm{NaNO}_{3}$, (b) CVs of Ru-RGO (pH 8) at various SR from $5 \mathrm{mV} \mathrm{s}^{-1}$ to $200 \mathrm{mV} \mathrm{s}^{-1}$, (c) effect of scan rate on specific capacitance of RGO (black line), $\mathrm{Ru}_{\text {nano-based }} \mathrm{RGO}\left(\mathrm{pH}\right.$ 4) (red line) and $\mathrm{Ru}_{\text {nano-based } \mathrm{RGO}}(\mathrm{pH}$ 8) (green line), (d) the effect of scan rate on the maximum current density obtained at charging and discharging process and (e) $\mathrm{CVs}$ of $\mathrm{Ru}_{n a n o}$-based $\mathrm{RGO}(\mathrm{pH}$ 8) obtained at various upper potential and the relation between the upper potential and specific capacitance (inset).

voltammetry in $1.0 \mathrm{M} \mathrm{NaNO}_{3}$ in the potential window from 0.0 to $0.9 \mathrm{~V}$ (see Fig. 4a). It is noticed that all the electrodes show a rectangular $\mathrm{CV}$ without appearing of any redox peaks indicating that the electric double layer capacitance shares the major contribution on the value of specific capacitance. $\mathrm{Ru}_{\text {nano- }}$ based RGO (prepared at $\mathrm{pH}$ 8) provides the highest specific capacitance $\left(C_{\mathrm{sp}}\right)$, reaching $159 \mathrm{~F} \mathrm{~g}^{-1}\left(140 \mathrm{mF} \mathrm{cm}^{-2}\right)$ at a scan rate of $50 \mathrm{mV} \mathrm{s}^{-1}$ and reaches $270 \mathrm{~F} \mathrm{~g}^{-1}\left(238.5 \mathrm{mF} \mathrm{cm}^{-2}\right)$ at a scan rate of $5 \mathrm{mV} \mathrm{s}^{-1}$ compared to $161.5 \mathrm{~F} \mathrm{~g}^{-1}\left(142.6 \mathrm{mF} \mathrm{cm}^{-2}\right)$ and $104 \mathrm{~F} \mathrm{~g}^{-1}\left(91.9 \mathrm{mF} \mathrm{cm}{ }^{-2}\right)$ at a scan rate of $5.0 \mathrm{mV} \mathrm{s}^{-1}$ for 
$\mathrm{Ru}_{\text {nano-based }} \mathrm{RGO}$ (prepared at $\mathrm{pH} 4.0$ ) and RGO, respectively. This indicates that inclusion of $\mathrm{Ru}$ nanoparticles acts as a spacer for RGO sheets and results in increasing the electrochemical capacitance of $\mathrm{Ru}_{\text {nano-based }} \mathrm{RGO}$ (prepared at $\mathrm{pH}$ 4)

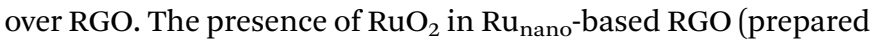
at pH 8.0) nearly doubles the value of the capacitance compared to $\mathrm{Ru}_{\text {nano-based }} \mathrm{RGO}$ (prepared at $\mathrm{pH} 4.0$ ) at $5.0 \mathrm{mV} \mathrm{s}^{-1}$. In order to gain more information about the charge storage capabilities of the ruthenium-based RGO composites, cyclic voltammetry was carried out at various scan rates ranging from 5.0 to $200 \mathrm{mV} \mathrm{s}^{-1}$ as shown in Fig. $4 \mathrm{~b}$. It is clearly shown that as the scan rate increases the specific capacitance decreases as the diffusional component of the current starts to increase. The CVs still have a rectangular shape up to $100 \mathrm{mV} \mathrm{s}^{-1}$ and the distortion in the CV shape at $200 \mathrm{mV} \mathrm{s}^{-1}$ is very small, indicating a typical electric double layer capacitance (EDLC) behavior. Fig. $4 \mathrm{c}$ reveals the calculated specific capacitance

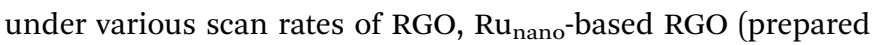
at $\mathrm{pH} 4.0$ ) and $\mathrm{Ru}_{\text {nano-based }} \mathrm{RGO}$ (prepared at $\mathrm{pH}$ 8.0), where again $\mathrm{Ru}_{\text {nano-based }} \mathrm{RGO}(\mathrm{pH}$ 8.0) provides the highest specific capacitance. By looking at the relation between the maximum current obtained during charging and discharging (Fig. 4d), we can conclude that $\mathrm{Ru}_{\text {nano-based } \mathrm{RGO}(\mathrm{pH}}$ 8.0) shows very good symmetry compared to $\mathrm{Ru}_{\text {nano-based }} \mathrm{RGO}(\mathrm{pH} 4.0)$ and the calculated diffusion coefficient of $\mathrm{Na}^{+}$ions through RGO,

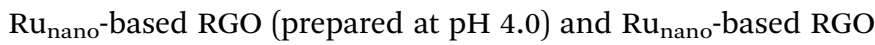
(prepared at pH 8.0) are $0.36 \times 10^{-8}, 1.3 \times 10^{-8}$ and $3 \times 10^{-8}$ $\mathrm{cm}^{2} \mathrm{~s}^{-1}$, respectively. The effect of upper potential on the specific capacitance of $\mathrm{Ru}_{\text {nano-based }} \mathrm{RGO}$ (pH 8.0) was investigated by CV and data are shown in Fig. 4e. The figure reveals that as the upper potential limit increases, the specific capacitance increases. This indicates the applicability of this supercapacitor to provide potentials up to $1.1 \mathrm{~V}$ in aqueous medium.

3.2.2 Galvanostatic charging/discharging measurements. Galvanostatic charging/discharging experiments were also conducted to evaluate the specific capacitance of $\mathrm{Ru}_{\text {nano-based }}$ RGO (prepared at pH 8.0) as shown in Fig. 5a. The specific capacitance of $\mathrm{Ru}_{\text {nano-based }} \mathrm{RGO}$ (prepared at $\mathrm{pH}$ 8) at current density $2.4 \mathrm{~A} \mathrm{~g}^{-1}$ is $80 \mathrm{~F} \mathrm{~g}^{-1}\left(70.6 \mathrm{mF} \mathrm{cm}{ }^{-2}\right)$ compared to $53.3 \mathrm{~F}$ $\mathrm{g}^{-1}\left(47 \mathrm{mF} \mathrm{cm}^{-2}\right)$ and $29.6 \mathrm{~F} \mathrm{~g}^{-1}\left(26.1 \mathrm{mF} \mathrm{cm}^{-2}\right)$ for $\mathrm{Ru}_{\text {nano- }}$ based RGO (prepared at pH 4.0) and RGO, respectively. It is also noticed that there is a slight change in the potential at the beginning of the discharge process, which reflects low ohmic resistance. The difference between the potential value at the onset of discharge, and the point at which a change in the slope of the discharge curve takes place is due to the $I R$-drop. As the current density increases, the specific capacitance decreases (see Fig. $5 \mathrm{~b}$ ); $\mathrm{Ru}_{\text {nano-based }}$ RGO (prepared at $\mathrm{pH}$ 8.0) shows a specific capacitance $40 \mathrm{~F} \mathrm{~g}^{-1}$ at high current density $20 \mathrm{~A} \mathrm{~g}^{-1}$ compared to $21.3 \mathrm{~F} \mathrm{~g}^{-1}$ and $13.3 \mathrm{~F} \mathrm{~g}^{-1}$ for $\mathrm{Ru}_{\text {nano-based } \mathrm{RGO}}$ (prepared at $\mathrm{pH} 4.0$ ) and $\mathrm{RGO}$, respectively. Both $\mathrm{Ru}_{\text {nano-based }}$ RGO prepared at $\mathrm{pH} 8.0$ and 4.0 show excellent cyclic stability even at a high current density of $24 \mathrm{~A} \mathrm{~g}^{-1}$, as shown in Fig. 5c. However, $\mathrm{Ru}_{\text {nano-based }} \mathrm{RGO}$ (prepared at $\mathrm{pH}$ 4) shows a continuous increase in the $C_{\mathrm{sp}}$ value upon cycling, reaching $158 \%$ capacitance retention after 5000 cycles. While, $\mathrm{Ru}_{\text {nano- }}$ based RGO (prepared at $\mathrm{pH}$ 8.0) showed an increase in the specific capacitance in the first 2600 cycles to reach $108 \%$ of the initial specific capacitance then achieved specific capacitance retention $92.5 \%$ after successive cycling for 5000 cycles. It is worth to mention that upon storage the electrode in the electrolyte solution overnight after performing 5000 cycles, its performance enhanced again to reach $146 \%$ of the initial performance as shown in Fig. 5d. This enhanced performance was also stable for another 100 cycles as shown in the inset of Fig. $5 \mathrm{~d}$. Based on the aforementioned results, $\mathrm{Ru}_{\text {nano-based }}$ RGO (prepared at pH 8.0) has very good cycling stability with the ability of enhancing its initial performance upon its storage in the electrolyte solution.

Ragon plots in Fig. 5e are used to compare the performances of the current surfaces, showing the relation between power density in $\mathrm{W} \mathrm{kg}^{-1}$ and the corresponding energy density in $\mathrm{Wh}$ $\mathrm{kg}^{-1}$. As shown in Fig. 5e, for a given power density the corresponding energy density is highest when using $\mathrm{Ru}_{\text {nano-based }}$ RGO (prepared at pH 8.0). This also shows an energy density of $7.7 \mathrm{~W} \mathrm{~h} \mathrm{~kg}^{-1}$ at $1766 \mathrm{~W} \mathrm{~kg}^{-1}$, holding an energy density of 4.3 $\mathrm{W} \mathrm{h} \mathrm{kg}{ }^{-1}$ at a higher power density $\left(8624 \mathrm{~W} \mathrm{~kg}^{-1}\right)$. The energy density decreases at high power densities due to the fast voltage decay at high power densities. ${ }^{31}$

The current supercapacitor shows higher specific capacitance and cyclic stability compared to that reported by Antiohos et al. ${ }^{32}$ at $90 \% \mathrm{MnO}-10 \% \mathrm{GO}\left(42.5 \pm 9.2 \mathrm{mF} \mathrm{cm}^{-2}\right)$ at scan rate $50 \mathrm{mV}$ $\mathrm{s}^{-1}$, in $1.0 \mathrm{M} \mathrm{NaNO}_{3}$. Li et al. ${ }^{6}$ reported $211.5 \mathrm{~F} \mathrm{~g}^{-1}$ at $2.0 \mathrm{mV} \mathrm{s}^{-1}$ in $1.0 \mathrm{M} \mathrm{Na}_{2} \mathrm{SO}_{4}$. Further, He et al. used $\mathrm{Ru}(20 \%) /$ mesoporous carbon and reported $269 \mathrm{~F} \mathrm{~g}^{-1}$ at $2.0 \mathrm{mV} \mathrm{s}^{-1}$ in $6.0 \mathrm{M} \mathrm{KOH},{ }^{11}$ while Xia et al. reported $238.6 \mathrm{~F} \mathrm{~g}^{-1}$ at scan rate $50 \mathrm{mV} \mathrm{s}^{-1}$ in $6.0 \mathrm{M} \mathrm{KOH}$ over $\mathrm{RGO} / \mathrm{CoMoO}_{4}$ material. ${ }^{33}$ Lou et al. ${ }^{34}$ synthesized $\mathrm{Ru} /$ porous activated carbon (derived from Moringa Oleifera fruit shells) composites using the bio-waste carbon source and ruthenium acetylacetonate as the co-feeding metal precursors (Ru/MOC). Ru/MOC provided a specific capacitance of $291 \mathrm{~F} \mathrm{~g}^{-1}$ (the area of the electrode is $1.0 \mathrm{~cm}^{2}$ ) at scan rate $10 \mathrm{mV} \mathrm{s}^{-1}$ in a potential range 0.0 to $800 \mathrm{mV}$ in $1.0 \mathrm{M} \mathrm{H}_{2} \mathrm{SO}_{4}$ and showed $90 \%$ of its original $C_{\mathrm{s}}$ after only 2000 cycles. Finally, Takikawa and coworkers reported $153 \mathrm{~F} \mathrm{~g}^{-1}$ at $0.125 \mathrm{~A} \mathrm{~g}^{-1}$ using $\mathrm{RuO}_{2} /$ activated carbon. ${ }^{12}$ The values reported in this work for $C_{\mathrm{sp}}$ are comparable to those measured earlier, ${ }^{18}$ using $\mathrm{RuO}_{2}(30.4 \%) / \mathrm{p}$-MWCNT in $1.0 \mathrm{M} \mathrm{H}_{2} \mathrm{SO}_{4}\left(231 \mathrm{~F} \mathrm{~g}^{-1}\right.$ at a scan rate of $\left.20 \mathrm{mV} \mathrm{s}^{-1}\right)$. Others reported the use of $\mathrm{RGO} / \mathrm{SnO}_{2}$-CNT, resulting in $218 \mathrm{~F} \mathrm{~g}^{-1}$ at scan rate $200 \mathrm{mV} \mathrm{s}^{-1}$ in $30 \mathrm{wt} \% \mathrm{KOH}(81 \%$ of initial capacitance remains after 6000 cycles). ${ }^{35}$ Although using $\mathrm{RuO}_{2}-\mathrm{RGO}$ as electrode materia ${ }^{14}$ shows higher specific capacitance (that may be due to the use of $1.0 \mathrm{M} \mathrm{H}_{2} \mathrm{SO}_{4}$ as electrolyte), the electrode material used in the present study $\left(\mathrm{Ru}_{\text {nano-based }} \mathrm{RGO}\right)$ shows higher cycling stability. And by taking into account the very small area of the used electrode $\left(0.283 \mathrm{~cm}^{2}\right)$, its use in capacitor applications can be considered as a good candidate for a commercial, green and easily-prepared supercapacitor.

3.2.3 Electrochemical impedance spectroscopy. Nyquist plots of EIS measurements of RGO Ru nano-based RGO (pH 4.0 and 8.0) in $1 \mathrm{M} \mathrm{NaNO}_{3}$ are shown in Fig. 6a. RGO shows a semicircle in the high frequency regions and a vertical line (with the lowest slope) in the low frequency regions. The intersection of semicircle with $x$-axis at high frequency region is 
a)

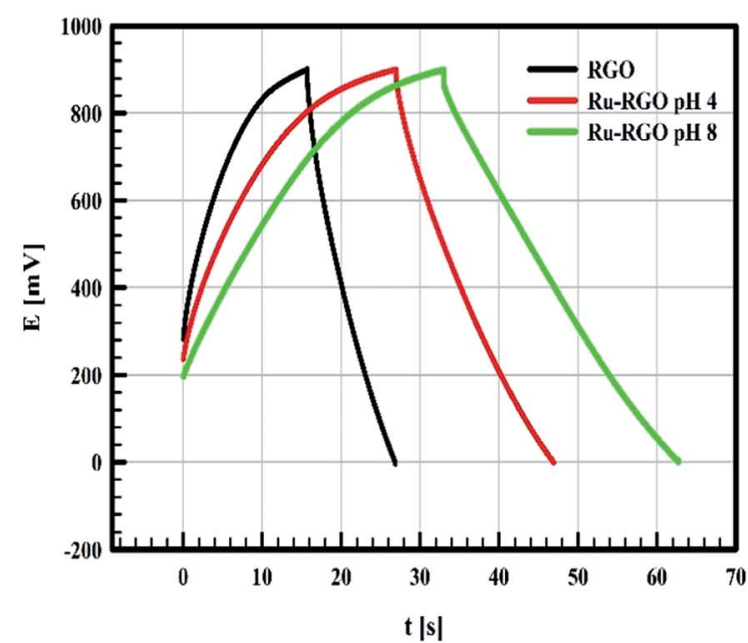

c)

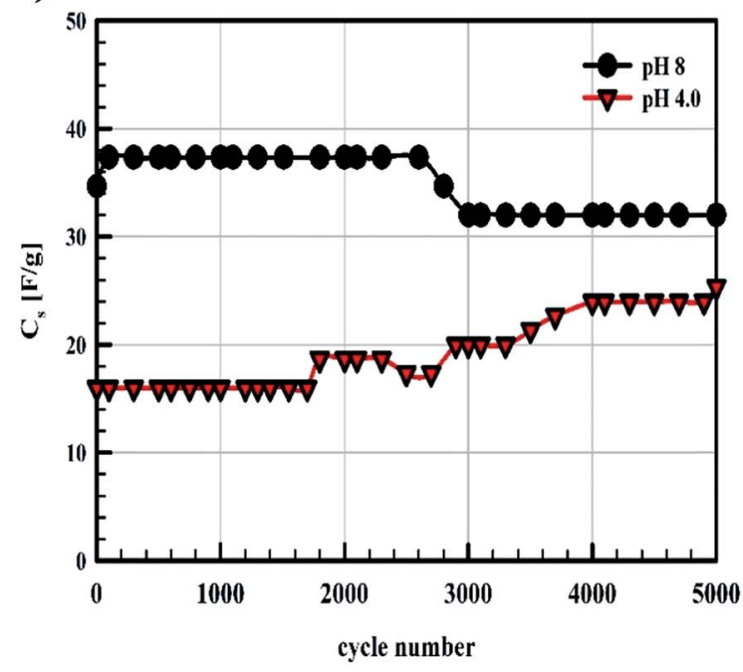

b)

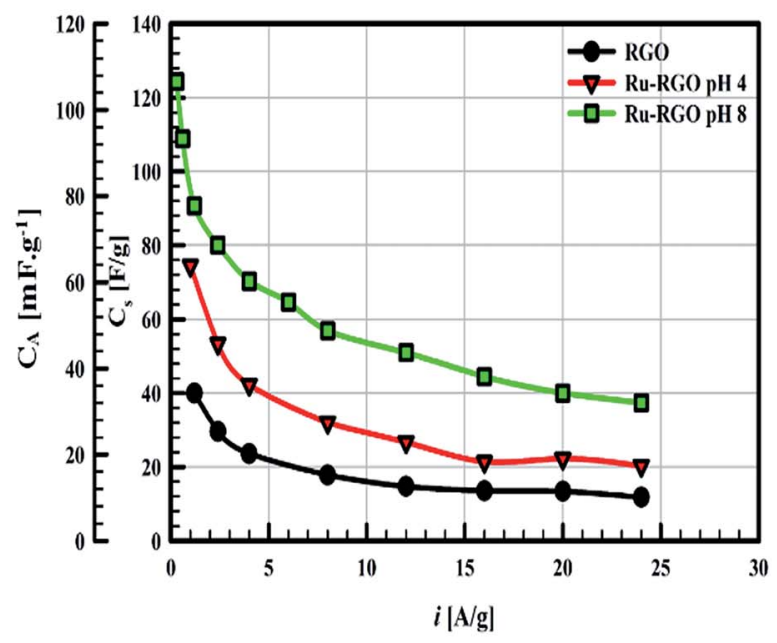

d)

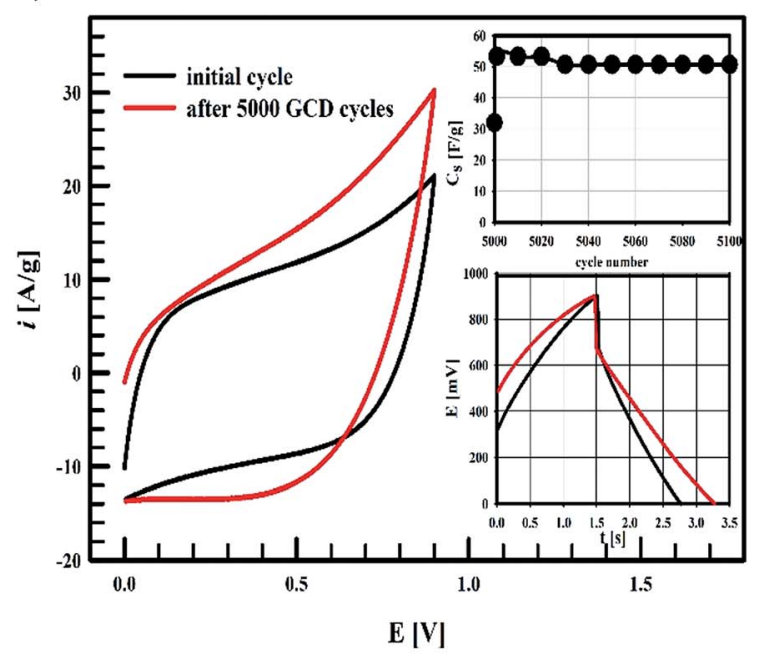

e)

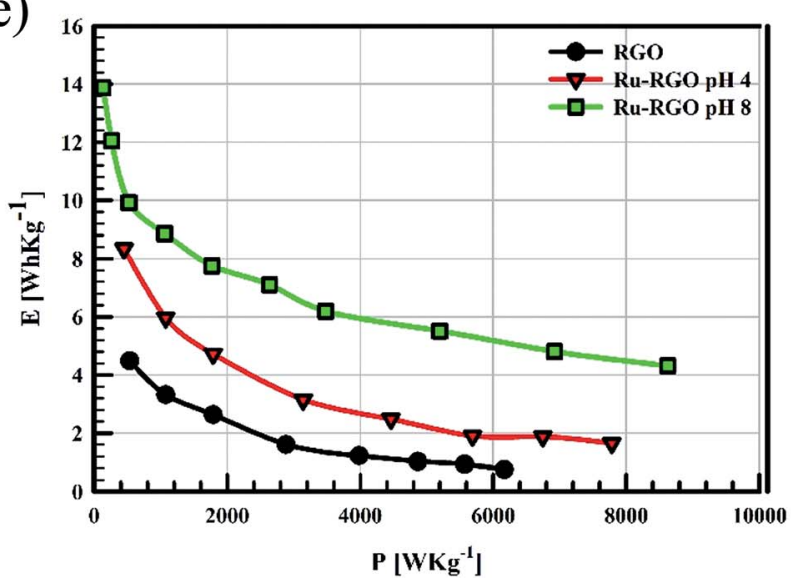

Fig. 5 (a) GCD curves of RGO (black line), Runano-based RGO (pH 4) (red line) and Runano-based RGO (pH 8) (green line) measured at current density $24 \mathrm{~A} \mathrm{~g}^{-1}$ in $1.0 \mathrm{M} \mathrm{NaNO}_{3}$, (b) the relation between the applied current density and the measured specific capacitance, (c) cycling stability of and Runano-based RGO (pH 8 and 4) measured at current density $24 \mathrm{~A} \mathrm{~g}^{-1}$ for 5000 cycles (d) the initially recorded CV compared to after performing $5000 \mathrm{GCD}$ cycles at $24 \mathrm{~A} \mathrm{~g}^{-1}$ followed by its storage overnight in the electrolyte solution. The inset is GCD at $24 \mathrm{~A} \mathrm{~g} \mathrm{~g}^{-1}$ and the measured specific capacitance recorded for another 100 cycles after the storage process. And (e) Ragon plot of RGO (black line), Runano-based

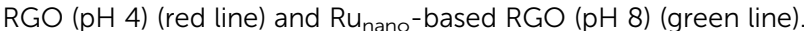


a)

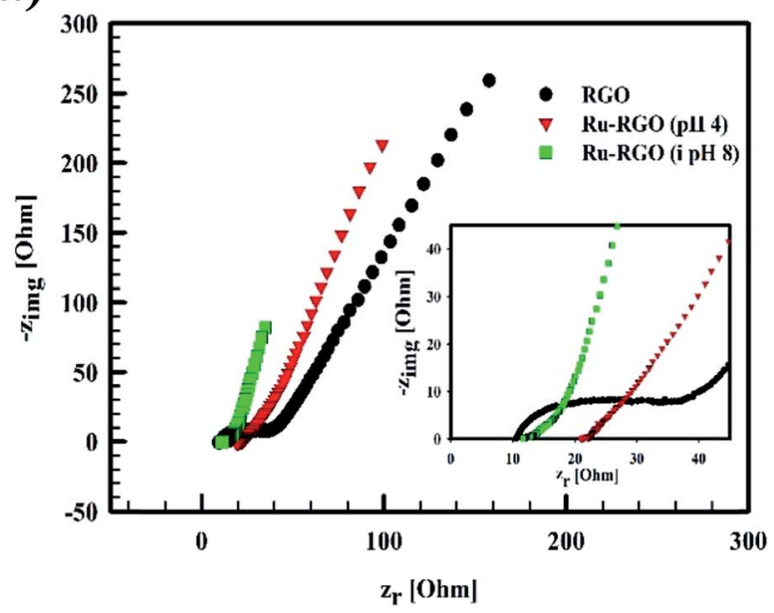

c)

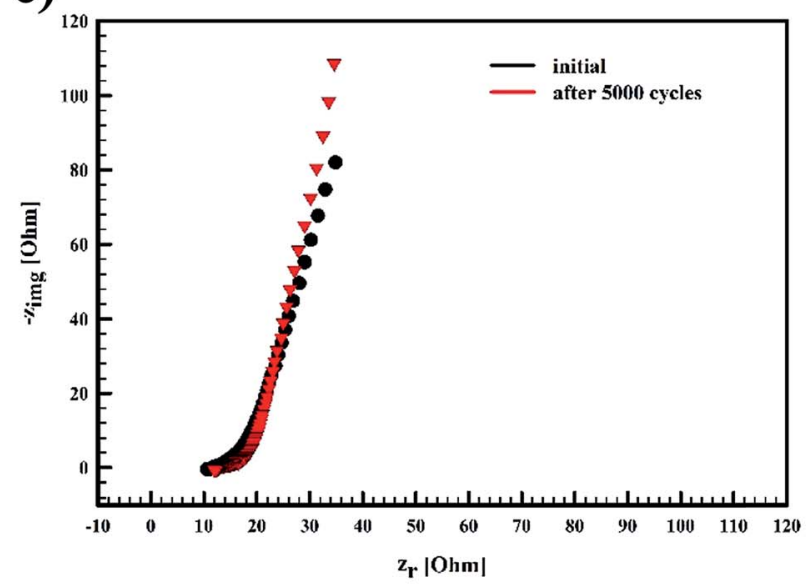

b)

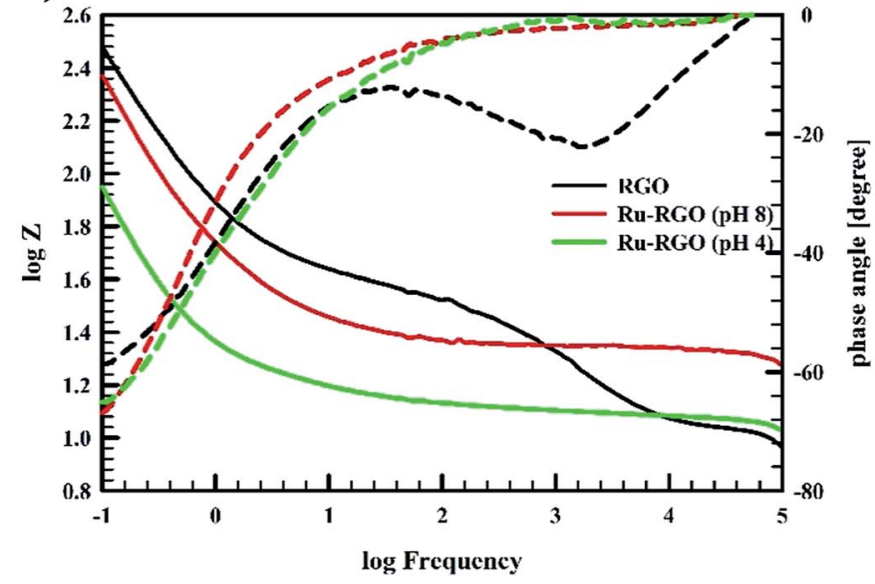

d)

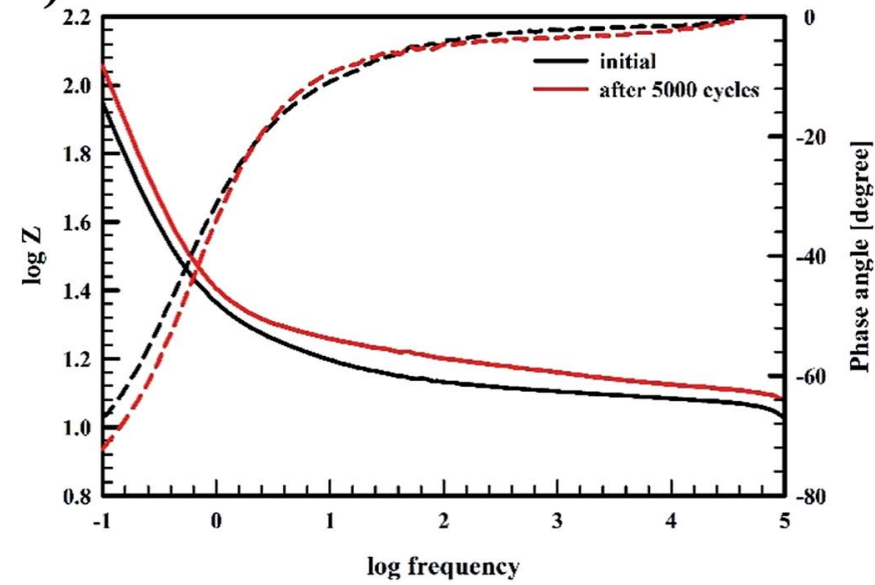

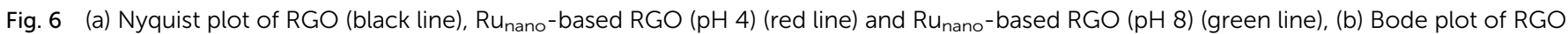
(black line), $\mathrm{Ru}$ nano-based RGO (pH 4) (red line) and $\mathrm{Ru}$ nano-based RGO (pH 8) (green line), (c) the initial Nyquist plot of Runano-based RGO (pH 8) (black) and after 5000 cycles (red) at $24 \mathrm{~A} \mathrm{~g}^{-1}$, and (d) the corresponding Bode plot.

the value of ESR and the diameter of the semicircle is the charge transfer resistance. Otherwise, both $\mathrm{Ru}_{\text {nano-based }} \mathrm{RGO}$ prepared at pH 4.0 and 8.0 do not show a semicircle at high frequencies, rather a distorted semicircle with a very small diameter is formed that indicates very low charge transfer resistance compared to RGO. The vertical line in the low frequency region is related to the diffusion resistance of the electrolyte at the electrode interface. ${ }^{6}$ The supercapacitors approach ideal behavior as the line at low frequency region becomes more vertical with increasing slope. As shown in Fig. 6a $\mathrm{Ru}_{\text {nano-based }} \mathrm{RGO}$ (prepared in $\mathrm{pH}$ 8.0) has a vertical line with relatively higher slopes compared to $\mathrm{Ru}_{\text {nano }}{ }^{-}$ based RGO (prepared at pH 4.0) and RGO, and tends to display better capacitive behavior. The calculated solution resistances for $\mathrm{RGO}, \mathrm{Ru}_{\text {nano-based }} \mathrm{RGO}$ (prepared at $\mathrm{pH} 4.0$ ) and $\mathrm{Ru}_{\text {nano-based }}$ RGO (prepared at pH 8) are $10.4 \Omega, 19.5 \Omega$ and $10.6 \Omega$, respectively.

The Bode plot in Fig. 6b reveals that $\mathrm{Ru}_{\text {nano-based } \mathrm{RGO}}$ (prepared at $\mathrm{pH}$ 8.0) has a phase angle $\varphi$ of $70^{\circ}$ at a frequency of $100 \mathrm{mHz}$, compared to $65^{\circ}$ for $\mathrm{Ru}_{\text {nano-based RGO (prepared at }}$ $\mathrm{pH} 4$ ) and $54^{\circ}$ for RGO. The value of $\varphi=70^{\circ}$ is close to the ideal capacitor at this frequency. Additionally, the time constants $(\tau)$ for $\mathrm{Ru}_{\text {nano-based }} \mathrm{RGO}$ (prepared at $\mathrm{pH}$ 8.0) can be calculated from the Bode plot, which is the time necessary to discharge the capacitor to $36.8 \%$ and it can be directly calculated by:

$$
\tau=\frac{1}{2 \pi f^{*}}
$$

where $f^{*}$ is the characteristic frequency (frequency at phase angle $45^{\circ}$ ).

It is established that the lower the time constant, the faster the charge/discharge characteristics. The calculated value of $\tau$ for $\mathrm{Ru}_{\text {nano-based }} \mathrm{RGO}$ (prepared at $\mathrm{pH}$ ) is $0.357 \mathrm{~s}$. This small value indicates fast charge/discharge properties of the current material. From the calculated time constant, the value of the maximum energy density can be deduced from the following relations:

$$
\begin{gathered}
\tau=\frac{E_{\max }}{2 P_{\max }} \\
P_{\max }=\frac{\Delta V^{2}}{4 m R_{\mathrm{ESR}}}
\end{gathered}
$$


The calculated $E_{\max }$ and $P_{\max }$ of $\mathrm{Ru}_{\text {nano-based RGO (prepared }}$ at $\mathrm{pH} 8$ ) are $15 \mathrm{~W} \mathrm{~h} \mathrm{~kg}^{-1}$ and $76.4 \mathrm{~kW} \mathrm{~kg}^{-1}$, respectively.

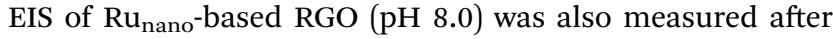
applying 5000 cycles at $24 \mathrm{~A} \mathrm{~g}^{-1}$ and the results were compared with the initial EIS measurement shown in Fig. 6c and d. We observe no significant change in the solution resistance after 5000 GCD cycles. However, the line at low frequency region became slightly more vertical after 5000 GCD cycles compared to the initial one. Moreover, there was no significant change in the phase angle as shown in the Bode plot (Fig. 6d).

\section{Conclusion}

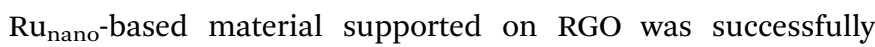
prepared by a one-pot, fast, green and $\mathrm{pH}$-controlled synthesis method with the aid of microwave irradiation and in the absence of any other reducing or stabilizing agent. No calcination steps were necessary to obtain crystalline Ru-nanoparticles.

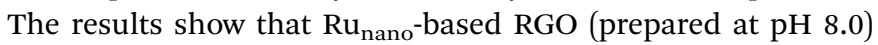
possesses the highest electrochemical capacitance compared to the one prepared at $\mathrm{pH}$ 4.0. Synthesis at $\mathrm{pH} 2.0$ was not suitable to reduce $\mathrm{Ru}^{3+}$ ions, and consequently did not show a good capacitive behavior. All measurements were carried out in a neutral electrolyte $\left(\begin{array}{llll}1.0 & \mathrm{M} \quad \mathrm{NaNO}_{3}\end{array}\right) . \mathrm{Ru}_{\text {nano-based }} \mathrm{RGO}$ (prepared at $\mathrm{pH} 8.0$ ) showed a specific capacitance of $270 \mathrm{~F} \mathrm{~g}^{-1}$ at scan rate of $5.0 \mathrm{mV} \mathrm{s}^{-1}\left(238.5 \mathrm{mF} \mathrm{cm}{ }^{-2}\right.$, surface area 0.283 $\left.\mathrm{cm}^{2}\right) . \mathrm{Ru}_{\text {nano }}-\mathrm{RGO}$ systems prepared at $\mathrm{pH} 8$ reveal a very good cycle stability even after 5000 cycles, where it showed a $C_{\mathrm{sp}}$ retention $92.5 \%$ that increased to $146 \%$ when the electrode stored in the electrolyte solution overnight. $\mathrm{Ru}_{\text {nano }}-\mathrm{RGO}$ (prepared at $\mathrm{pH}$ 8.0) showed a maximum power density of $76.4 \mathrm{~kW} \mathrm{~kg}^{-1}$ with a maximum energy density of $15.0 \mathrm{~W} \mathrm{~h} \mathrm{~kg}^{-1}$.

\section{Acknowledgements}

The authors would like to acknowledge the partial financial support from Cairo University through the Vice President Office for Research Funds.

\section{References}

1 Y. Cao, B. Lin, Y. Sun, H. Yang and X. Zhang, J. Alloys Compd., 2015, 638, 204-213.

2 Z. B. Zhou, M. Benbouzid, J. F. Charpentier, F. Scuiller and T. H. Tang, Renewable Sustainable Energy Rev., 2013, 18, 390-400.

3 J. W. Leea, J. M. Kob and J.-D. Kima, Electrochim. Acta, 2012, 85, 459-466.

4 P. Simon and Y. Gogotsi, Nat. Mater., 2008, 7, 845-854.

5 N. Lin, J. Tian, Z. Shan, K. Chen and W. Liao, Electrochim. Acta, 2013, 99, 219-224.

6 Z. Li, J. Wanga, S. Liu, X. Liu and S. Yang, J. Power Sources, 2011, 196, 8160-8165.

7 C. G. Liu, Z. N. Yu, D. Neff, A. Zhamu and B. Z. Jang, Nano Lett., 2010, 10, 4863-4868.

8 M. F. El-Kady, V. Strong, S. Dubin and R. B. Kaner, Science, 2012, 335, 1326-1330.
9 P. Wang, H. Liu, Y. Xu, Y. Chen, J. Yang and Q. Tan, Electrochim. Acta, 2016, 194, 211-218.

10 J. Y. Hwang, M. F. El-Kady, Y. Wang, L. Wang, Y. Shao, K. Marsh, J. M. Ko and R. B. Kaner, Nano Energy, 2015, 18, 57-70.

11 X. He, K. Xie, R. Li and M. Wu, Mater. Lett., 2014, 115, 96-99.

12 X. J. He, Y. J. Geng, S. Oke, K. Higashi, M. Yamamoto and H. Takikawa, Synth. Met., 2009, 159, 7-12.

13 X. Leng, J. Zou, X. Xiong and H. He, J. Alloys Compd., 2015, 653, 577-584.

14 L. Na, J. Tian, Z. Shan, C. Kuan and W. Liao, Electrochim. Acta, 2013, 99, 219-224.

15 R. Rakhi, W. Chen, D. Cha and H. Alshareef, J. Mater. Chem., 2011, 21, 16197-16204.

16 N. Soin, S. S. Roy, S. K. Mitra, T. Thundat and J. A. McLaughlin, J. Mater. Chem., 2012, 22, 14944-14950.

17 L. Deng, J. Wang, G. Zhu, L. Kang, Z. Hao, Z. Lei, Z. Yang and Z.-H. Liu, J. Power Sources, 2014, 248, 407-415.

18 X. Liu, T. A. Huber, M. C. Kopac and P. G. Pickup, Electrochim. Acta, 2009, 54, 7141-7147.

19 N. I. Kovtyukhova, P. J. Ollivier, B. R. Martin, T. E. Mallouk, S. A. Chizhik, E. V. Buzaneva and A. D. Gorchinskiy, Chem. Mater., 1999, 11, 771-778.

20 N. F Atta, H. K. Hassan and A. Galal, Anal. Bioanal. Chem., 2014, 406, 6933-6942.

21 M. J. Collins Jr, Future Med. Chem., 2010, 2, 151-155.

22 Y.-J. Zhu and F. Chen, Chem. Rev., 2014, 114, 6462-6555.

23 R. C. Rocha, M. G. Brown, C. H. Londergan, J. C. Salsman, C. P. Kubiak and A. P. Shreve, J. Phys. Chem. A, 2005, 109, 9006-9012.

24 L. M. M. Tejada, A. Muñoz, M. A. Centeno and J. A. Odriozola, J. Raman Spectrosc., 2016, 47, 189-197.

25 R.-R. Bi, X.-L. Wu, F.-F. Cao, L.-Y. Jiang, Y.-G. Guo and L.-J. Wan, J. Phys. Chem. C, 2010, 114, 2448-2451.

26 J. Y. Shen, A. Adnot and S. Kaliaguine, Appl. Surf. Sci., 1991, 51, 47-60.

27 J. C. Fuggle, T. E. Madey, M. Steinkilberg and D. Menzel, Surf. Sci., 1975, 52, 521-541.

28 M. Y. Ho, P. S. Khiew, D. Isa, T. K. Tan, W. S. Chiu and C. H. Chia, Nano, 2014, 9(6), 1430002-1430027.

29 K. Seung and Y. B.-H. Kim, Electrochim. Acta, 2015, 186, 337344.

30 P. K. Shen, C.-Y. Wang, S. P. Jiang, X. Sun and J. Zhan, Electrochemical Energy, advanced materials and technology, CRC Press, 2016.

31 P. Tamilarasan and S. Ramaprabhu, Energy, 2013, 51, 374-381. 32 D. Antiohos, K. Pingmuang, M. S. Romano, S. Beirne, T. Romeoa, P. Aitchison, A. Minett, G. Wallace, S. Phanichphant and J. Chen, Electrochim. Acta, 2013, 101, 99-108.

33 X. Xia, W. Lei, Q. Hao, W. Wang and X. Wang, Electrochim. Acta, 2013, 99, 253-261.

34 B.-S. Lou, P. Veerakumar, S.-M. Chen, V. Veeramani, R. Madhu and S.-B. Liu, Sci. Rep., 2016, 6, 19949, DOI: 10.1038/srep19949. PMID: 26818461.

35 R. B. Rakhi and H. N. Alshareef, J. Power Sources, 2011, 196, 8858-8865. 